\title{
Hyperoxia Attenuates Endothelial-Mediated Vasodilation in the Human Skin
}

\author{
Fumio YAMAZAKI \\ Department of Clinical Pathophysiology, School of Health Sciences, University of Occupational and Environmental Health, \\ Kitakyushu, 807-8555 Japan
}

\begin{abstract}
The influence of hyperoxia on the cutaneous vasodilator responses to iontophoretic applications of acetylcholine (ACh) and sodium nitroprusside (SNP) was examined in healthy subjects. The breathing of $100 \% \mathrm{O}_{2}$ decreased $(P<0.05)$ the
\end{abstract}

Key words: skin blood flow, oxygen, endothelium.

vasodilator response to Ach, but not to SNP, suggesting that hyperoxia attenuates endothelial-mediated vasodilation of the human skin.
$\mathrm{O}$ xygen breathing is widely used under therapeutic and experimental situations in medicine. An understanding of hyperoxic effects on the circulatory system is fundamental to the understanding of the efficacy of hyperbaric oxygen therapy in clinical situations, though the effect of hyperoxia on the skin circulation is still unclear. It has been reported that supplemental oxygen increases peripheral vascular resistance $[1,2]$ and decreases the limb vasodilator response to forearm ischemia [3]. Since the sympathetic nerve activity to muscle is decreased or unchanged under hyperoxic conditions $[4,5]$, this peripheral vasoconstriction may be associated with nonsympathetic mechanisms. Previous studies suggested that arterial blood $\mathrm{O}_{2}$ tension influences the endothelium-derived factors that contribute to the maintenance of vascular tone $[6,7]$. Further, it has been demonstrated in vitro that superoxide anions derived from hyperoxia react rapidly with nitric oxide (NO) [8]. Therefore hyperoxia may impair the function of endothelium-derived vasoactive factors, such as NO in the skin. In this study, we investigated the effects of hyperoxia on the responses of skin microcirculation to the iontophoretic application of acetylcholine (ACh), an endothelium-dependent vasodilator, and sodium nitroprusside (SNP), an NO donor.

\section{Methods}

Subjects. Ten male volunteers participated in the experiments. Their average age was $23 \pm 1$ (SE) years, average weight $67 \pm 3 \mathrm{~kg}$, and average height $173 \pm 2 \mathrm{~cm}$. All subjects were healthy nonsmokers with no history of cardiovascular disease. Written informed consent was obtained after a thorough explanation of the present study, including its purpose and risks. The experiments were approved by the Ethics Committee of Medical Care and Research of the University of Occupational and Environmental Health.

Measurements. Skin blood flow (SkBF) was monitored continuously with laser-Doppler flowmeters (LDF) (ALF21, Advance, Tokyo). LDF measurements are specific to the skin and are not influenced by blood flow to underlying skeletal muscle [9]. As an index of core temperature, sublingual temperature (Tsl) was measured with a polyethylene-sealed thermocouple. Skin temperature (Tsk) was measured using copper-constantan thermocouples on the chest, upper back, lower back, abdomen, thigh, calf, and forearm, and mean Tsk was calculated [10]. Heart rate (HR) was determined from the electrocardiogram $\left(\mathrm{CM}_{5}\right.$ lead). Mean arterial pressure (MAP) was measured continuously from a cuff on the middle finger (Finapres, Ohmeda, Madison, WI). Arterial $\mathrm{O}_{2}$ saturation $\left(\mathrm{SaO}_{2}\right)$ was measured from the index finger with a pulse oximeter (Biox3740, Ohmeda, Louisville, CO). End-tidal $\mathrm{CO}_{2}\left(\mathrm{ETCO}_{2}\right)$ was monitored with a $\mathrm{CO}_{2}$ analyzer (CapnoQuant 9040, EnviteC, Wismar).

Experimental procedures and protocols. Two experiments consisting of different protocols were conducted under constant environmental conditions (ambient temperature, $26^{\circ} \mathrm{C}$; relative humidity, $50 \%$ ). Each subject participated in the two experiments on separate days. The protocols were as follows.

Protocol 1. Effect of hyperoxia on endothelium-dependent vasodilation in the skin: The subjects wore shorts and T-shirts and rested in a supine position for $\sim 30 \mathrm{~min}$. During this period, cuffs for measuring arterial pressure, ther-

Received on Sep 27, 2006; accepted on Dec 10, 2006; released online on Dec 16, 2006; doi:10.2170/physiolsci.SC011006 Correspondence should be addressed to: Fumio Yamazaki, Department of Clinical Pathophysiology, School of Health Sciences, University of Occupational and Environmental Health (UOEH), 1-1 Iseigaoka, Yahatanishi-ku, Kitakyushu, 807-8555 Japan. Phone: +81-93-691-7162; +Fax: +81-93-691-7127; E-mail: yamazaki@health.uoeh-u.ac.jp 
mocouples, and flow probes were applied. The flow probes were held in place by custom-built Plexiglas chambers that enable the application of drugs via iontophoresis at the site of SkBF monitoring. The subjects breathed through a low-resistance Hans Rudolph valve, the inspiratory side of which was connected to Douglas bags containing $100 \% \mathrm{O}_{2}$. To prevent any reduction of $\mathrm{PCO}_{2}$ induced by hyperventilation during the breathing of $100 \%$ $\mathrm{O}_{2}$ [11], baseline $\mathrm{ETCO}_{2}$ was maintained throughout the experiment by adding $\mathrm{CO}_{2}$ from a high-pressure source of $100 \% \mathrm{CO}_{2}$ to the inspiratory side of the valve. The responses to the $\mathrm{ACh}$ vehicle (distilled water) and $\mathrm{ACh}$ were measured at each ventral site on both forearms. Iontophoretic applications of 1\% ACh (Sigma, St. Louis, $\mathrm{MO})$ were performed twice on the different sites of skin during the breathing of room air $\left(21 \% \mathrm{O}_{2}\right)$ or $100 \% \mathrm{O}_{2}$ (i.e., a total of 4 times in one experiment). The order of the tests was randomized. ACh was delivered using an anodal current: $7 \times(0.1 \mathrm{~mA}$ for $20 \mathrm{~s})$, followed by $1 \times(0.2 \mathrm{~mA}$ for 20 s), with a 60-s interval between doses (Fig. 1A) [12]. A 60-s interval between each iontophoresis period was required to achieve the plateau of the response following each delivery of ACh.

Protocol 2. Effect of hyperoxia on endothelium-independent vasodilation in the skin: This experiment was performed using the procedure and devices similar to those used in protocol 1. The responses to the SNP vehicle (distilled water) and SNP were measured at each ventral site on both forearms. Iontophoretic applications of $0.1 \% \mathrm{SNP}$ (Sigma, St. Louis, MO) were performed twice on the different sites of skin during the breathing of room air or $100 \% \mathrm{O}_{2}$ (i.e., a total of 4 times in one experiment). The order of the tests was randomized. SNP was delivered using a cathodal current: $2 \times(0.1 \mathrm{~mA}$ for $20 \mathrm{~s})$, followed by $1 \times(0.2 \mathrm{~mA}$ for $20 \mathrm{~s})$, with a 180 -s interval between doses (Fig. 2A) [12]. Preliminary studies showed that the response to SNP required a longer time to develop than that to ACh. The applications of SNP and the vehicle were limited to three because more multiple applications of the vehicle by using cathodal current induced a marked increase of SkBF, and the vasodilator effect of SNP itself became obscure.

Data processing and statistical analysis. The measured variables were recorded by a data logger (DE1200 universal, NEC Sanei, Tokyo, Japan) every $5 \mathrm{~s}$ and averaged every 1 min. Cutaneous vascular conductance (CVC) was calculated from the ratio of SkBF to MAP. The changes in CVC were expressed as percent change from the normoxic control level. The values for CVC from pairs of identically treated sites (responses to ACh, SNP, or their vehicles) were averaged for each subject.

The effects of hyperoxia, vasoactive drug, or drug vehicle on changes in CVC were evaluated using two-way repeated measures ANOVA and the Student-NewmanKeuls test. Differences between the control and hyperoxic periods in each value were analyzed using Student's paired $t$-tests. $P<0.05$ was considered significant.

\section{Results}

Table 1 shows baseline cardiovascular and temperature measurements from the two levels of $\mathrm{O}_{2}$ breathing. The breathing of $100 \% \mathrm{O}_{2}$ increased $(P<0.001) \mathrm{SaO}_{2}$, but $\mathrm{ETCO}_{2}$ was maintained at a constant level throughout the $\mathrm{O}_{2}$ inhalation experiments. The breathing of $100 \% \mathrm{O}_{2}$ tended to decrease $(P=0.058) \mathrm{HR}$ and to increase MAP $(P=0.084)$, but these small changes did not achieve statistical significance. Breathing $100 \% \mathrm{O}_{2}$ did not significantly alter Tsl, mean Tsk, or forearm Tsk.

The changes in forearm CVC in response to iontophoresis of ACh and the ACh vehicle are shown in Fig. 1. The breathing of $100 \% \mathrm{O}_{2}$ decreased $(P<0.05) \mathrm{CVC}$ by $8.3 \pm 3.6 \%$ from the baseline level during $21 \% \mathrm{O}_{2}$ breathing in protocol 1. The iontophoretic application of $\mathrm{ACh}$ increased $(P<0.0001) \mathrm{CVC}$, though the response to $\mathrm{ACh}$ was attenuated $(P<0.05)$ during $100 \% \mathrm{O}_{2}$ breathing compared to $21 \% \mathrm{O}_{2}$ breathing (Fig. 1B). The iontophoresis of the ACh vehicle slightly but significantly increased CVC, but breathing $100 \% \mathrm{O}_{2}$ did not significantly alter the CVC responses to the vehicle (Fig. 1B). The difference between the response in CVC to Ach and that to the vehicle was smaller $(P<0.01)$ during $100 \% \mathrm{O}_{2}$ breathing than during $21 \% \mathrm{O}_{2}$ breathing (Fig. 1C).

The changes in forearm CVC in response to iontophoresis of SNP and the SNP vehicle are shown in Fig. 2. The breathing of $100 \% \mathrm{O}_{2}$ decreased $(P<0.05) \mathrm{CVC}$ by $10.9 \pm 2.6 \%$ from the baseline level during $21 \% \mathrm{O}_{2}$ breathing in protocol 2. The iontophoretic application of SNP increased $(P<0.0001)$ CVC during both $21 \%$ and $100 \% \mathrm{O}_{2}$ breathing, but these responses were not significantly different $(P=0.50)$ (Fig. 2B). The iontophoresis of the SNP vehicle also significantly increased CVC, but this response was not altered $(P=0.55)$ by breathing $100 \% \mathrm{O}_{2}$ (Fig. 2B). The response of CVC to SNP minus that to the SNP vehicle did not significantly differ between $21 \% \mathrm{O}_{2}$ and $100 \% \mathrm{O}_{2}$ breathing $(P=0.60)$ (Fig. 2C).

Table 1. Physiological variables during $21 \%$ and $100 \% \mathrm{O}_{2}$ breathing.

\begin{tabular}{lrc}
\hline & $21 \% \mathrm{O}_{2}$ & $100 \% \mathrm{O}_{2}$ \\
\hline $\mathrm{SaO}_{2}(\%)$ & $97.5 \pm 0.2$ & $99.8 \pm 0.1^{*}$ \\
$\mathrm{ETCO}_{2}(\%)$ & $5.5 \pm 0.1$ & $5.5 \pm 0.1$ \\
$\mathrm{HR}($ beats/min) & $61.3 \pm 2.0$ & $59.4 \pm 1.7$ \\
$\mathrm{MAP}(\mathrm{mmHg})$ & $87.7 \pm 2.7$ & $91.3 \pm 3.0$ \\
$\mathrm{Tsl}\left({ }^{\circ} \mathrm{C}\right)$ & $36.6 \pm 0.1$ & $36.6 \pm 0.1$ \\
Mean Tsk $\left({ }^{\circ} \mathrm{C}\right)$ & $34.8 \pm 0.1$ & $34.8 \pm 0.1$ \\
Forearm Tsk $\left({ }^{\circ} \mathrm{C}\right)$ & $32.2 \pm 0.2$ & $32.0 \pm 0.2$
\end{tabular}

Values are mean $\pm \mathrm{SE} . \mathrm{SaO}_{2}$, arterial $\mathrm{O}_{2}$ saturation; $\mathrm{ETCO}_{2}$, endtidal $\mathrm{CO}_{2}$; HR, heart rate; MÄP, mean arterial pressure; Tsl, sublingual temperature; Tsk, skin temperature. ${ }^{*} P<0.05$ vs. $21 \%$ $\mathrm{O}_{2}$. 

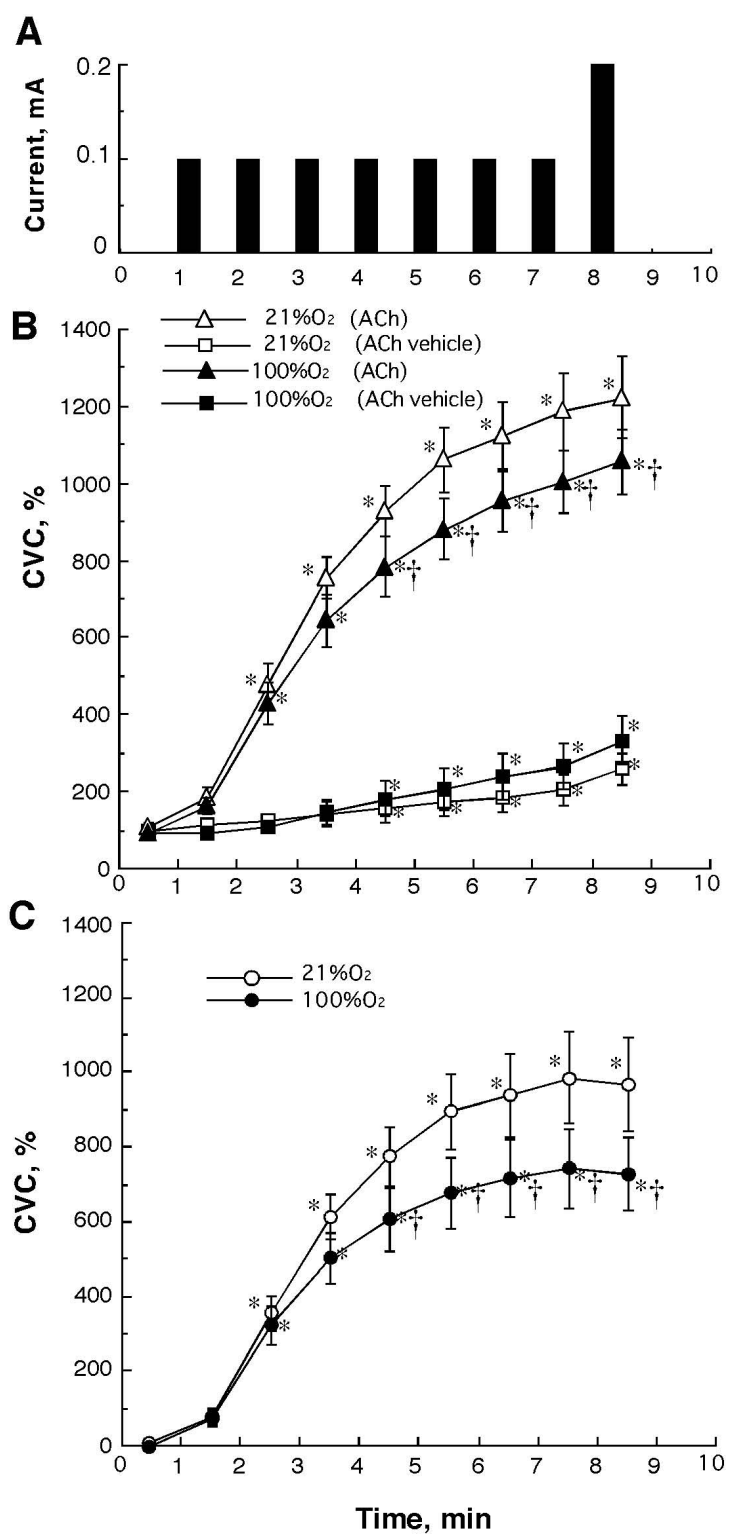

Fig. 1. (A) Protocol for the iontophoretic application of $\mathrm{ACh}$ and vehicle. (B) Cutaneous vasodilation in response to the iontophoresis of ACh and ACh vehicle during $21 \%$ and $100 \%$ $\mathrm{O}_{2}$ breathing. (C) Responses of CVC following the iontophoresis of ACh minus the ACh vehicle response during $21 \%$ and $100 \% \mathrm{O}_{2}$ breathing. ${ }^{*} P<0.05$ vs. baseline control, $\dagger P<$ 0.05 vs. $21 \% \mathrm{O}_{2}$.

\section{Discussion}

The major findings from the present study are twofold: (i) hyperoxia decreased the cutaneous vasodilator response to an application of $\mathrm{ACh}$, but (ii) it did not alter the cutaneous vasodilator response to the application of SNP in healthy humans. These findings suggest that hyperoxia acts to constrict the vasculature via altered endothelial function, but it does not alter the vascular reactivity in response to NO in the skin.

In the present study, isocapnic hyperoxia as a result of breathing $100 \% \mathrm{O}_{2}$ induced cutaneous vasoconstriction. High arterial blood $\mathrm{O}_{2}$ tension has been associated with
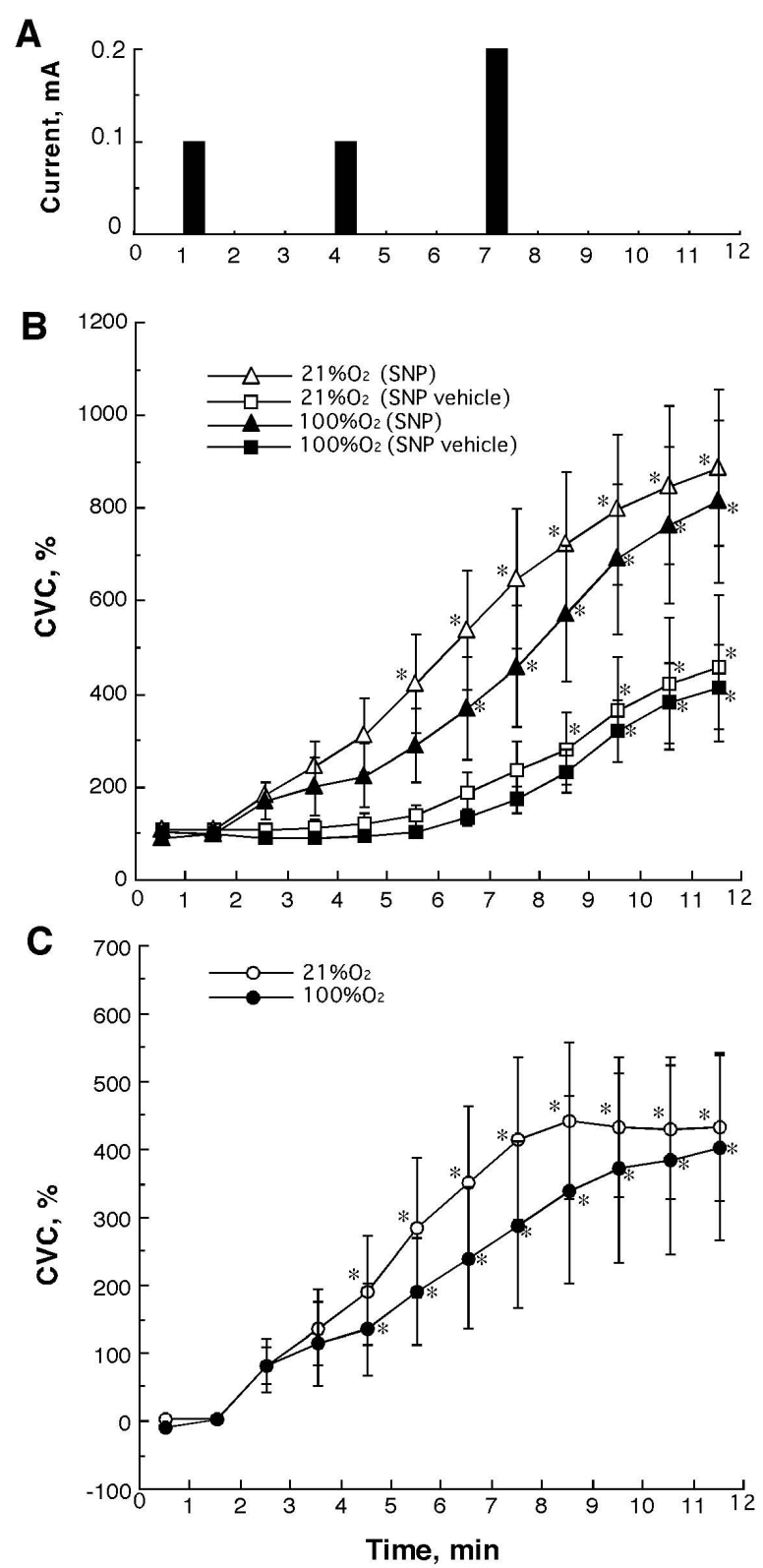

Fig. 2. (A) Protocol for the iontophoretic application of SNP and vehicle. (B) Cutaneous vasodilation in response to the iontophoresis of SNP and SNP vehicle during $21 \%$ and $100 \%$ $\mathrm{O}_{2}$ breathing. (C) Responses of CVC following the iontophoresis of SNP minus the SNP vehicle response during $21 \%$ and $100 \% \mathrm{O}_{2}$ breathing. ${ }^{*} P<0.05$ vs. baseline control.

the increased production of superoxide anions as well as other reactive oxygen species (ROS) [13]. Vitamin C, an antioxidant, prevents hyperoxia-mediated vasoconstriction of the limb in healthy subjects as well as in patients with congestive heart failure [14]. These observations suggest that hyperoxia-associated ROS are mediators of this vasoconstrictor response, though the mechanism by which hyperoxia might generate ROS near the skin vascular wall is unclear.

ACh elicits vasodilation through a complex sequence of events: When applied to blood vessels, ACh binds to 
muscarinic receptors on the surface of endothelial cells, which activates specific $\mathrm{G}$ proteins, resulting in the production of NO from L-arginine. Then NO diffuses across the intercellular gap and binds to the heme moiety of guanylate cyclase in the smooth muscle cells. This induces a rise in cyclic guanosine monophosphate and consequently relaxation [15]. Some animal studies have suggested that hyperoxia decreases the bioavailability of $\mathrm{NO}[7,16]$. Besides eliciting NO production, ACh also stimulates the release of the vasodilators prostaglandins and the putative endothelium-derived hyperpolarizing factor from the endothelium $[17,18]$. Therefore the attenuated ACh response of the skin vessel during hyperoxia may be attributed to impairments in one or several of these processes.

The techniques of laser-Doppler flowmetry and iontophoresis enabled the continuous measurement of SkBF responses to vasoactive agents. Although iontophoresis provides a noninvasive technique to introduce charged substances across the surface of the skin, it is important to consider the possible shortcomings of this technique. For example, current alone may affect tissue perfusion. In the present study, for example, vasodilation to the drug vehicle was observed with both anodal and cathodal currents. Therefore the vasodilator responses during iontophoretic applications of ACh and SNP contain the effects both of drugs and of the electrical current. If these effects independently induce vasodilation, the interpretation of the major findings of this study will not be altered for three reasons: (i) the cutaneous vasodilator response to current alone did not differ between normal air breathing and $100 \% \mathrm{O}_{2}$ breathing (Figs. 1B and 2B); (ii) the vasodilator response following the iontophoresis of ACh minus drug vehicle response during $100 \% \mathrm{O}_{2}$ breathing was larger than that during $21 \% \mathrm{O}_{2}$ breathing (Fig. 1C); and (iii) the vasodilator response following the iontophoresis of SNP minus drug vehicle response during $100 \% \mathrm{O}_{2}$ breathing did not differ from that during $21 \% \mathrm{O}_{2}$ breathing (Fig. 2C). However, if electrical current modulates the vasodilator effects of drugs and an additive model in the vasodilator effects is not applicable to this case, the iontophoresis technique cannot find out the net effects of drugs. Moreover, the finding that the vasodilator responses to SNP did not statistically differ between $21 \% \mathrm{O}_{2}$ and $100 \%$ $\mathrm{O}_{2}$ breathing may be due to the larger and more variable vasodilator effect of cathodal current compared with anodal current (Figs. 1B and 2B). Thus it is possible that the use of cathodal current concealed the potential effect of hyperoxia on the bioavailability of NO in the skin.
In conclusion, it is suggested that isocapnic hyperoxia attenuates the endothelium-dependent vasodilation of the skin in normothermic humans. Further study is needed to delineate the hyperoxic effect in the NO vasodilator pathway.

The author appreciates Dr. John M. Johnson for his critical reading of the manuscript and useful comments. Appreciation is also expressed to the participants in this study. This study was partly supported by a Grant-in-Aid for Scientific Research (C) from the Japan Society for the Promotion of Science (17500453).

\section{REFERENCES}

1. Daly WJ, Bondurat S. Effects of oxygen breathing on the heart rate, blood pressure and cardiac index of normal men — resting, with reactive hyperemia and after atropine. J Clin Invest. 1962;41:126-32.

2. Eggers GWN, Paley HW, Leonard JJ, Warren JV. Hemodynamic responses to oxygen breathing in man. J Appl Physiol. 1961;17:75-9.

3. Crawford P, Good PA, Gutierrez E, Feinberg JH, Boehmer JP, Silber DH, Sinoway LI. Effects of supplemental oxygen on forearm vasodilation in humans. J Appl Physiol. 1997;82:1601-6.

4. Jones PP, Davy KP, Seals DR. Influence of gender on the sympathetic neural adjustments to alterations in systemic oxygen levels in humans. Clin Physiol. 1999;19:153-60.

5. Seals DR, Johnson DG, Fregosi RF. Hyperoxia lowers sympathetic activity at rest but not during exercise in humans. Am J Physiol. 1991;260:R873-8.

6. Messina EJ, Sun D, Koller A, Wolin MS, Kaley F. Increases in oxygen tension evoke arteriolar constriction by inhibiting endothelial prostaglandin synthesis. Microvasc Res. 1994;48:151-60.

7. Mouren S, Souktani R, Beaussier M, Abdenour L, Arthaud M, Duvelleroy M, Vicaut $E$. Mechanisms of coronary vasoconstriction induced by high arterial oxygen tension. Am J Physiol Heart Circ Physiol. 1997;272:H67-75.

8. Rubanyi GM, Vanhoutte PM. Superoxide anions and hyperoxia inactivate endothelium-derived relaxing factor. Am J Physiol Heart Circ Physiol. 1986;250:H822-7.

9. Saumet JL, Kellogg DL Jr, Taylor WF, Johnson JM. Cutaneous laser-Doppler flowmetry: influence of underlying muscle blood flow. J Appl Physiol.1988;65:478-81.

10. Taylor WF, Johnson JM, O'Leary D, Park MK. Effect of high local temperature on reflex cutaneous vasodilation. J Appl Physiol. 1984;57:191-6.

11. Becker HF, Polo O, McNamara SG, Berthon-Jones M, Sullivan CE. Effect of different levels of hyperoxia on breathing in healthy subjects. J Appl Physiol. 1996;81:1683-90.

12. Morris SJ, Shore AC, Tooke JE. Responses of the skin microcirculation to acetylcholine and sodium nitroprusside in patients with NIDDM. Diabetologia. 1995;38:1337-44

13. Jamieson $D$, Chance $B$, Cadenas $E$, Boveris $A$. The relation of free radical production to hyperoxia. Ann Rev Physiol. 1986;48:703-19.

14. Mak S, Egri Z, Tanna G, Colman R, Newton GE. Vitamin C prevents hyperoxiamediated vasoconstriction and impairment of endothelium-dependent vasodilation. Am J Physiol Heart Circ Physiol. 2002;282:H2414-21.

15. Vallance $P$, Collier J. Biology and clinical relevance of nitric oxide. BMJ.1994;309:453-7.

16. Sauls BA, Boegehold MA. Arteriolar wall $\mathrm{PO}_{2}$ and nitric oxide release during sympathetic vasoconstriction in the rat intestine. Am J Physiol Heart Circ Physiol. 2000;279:H484-91.

17. Kellogg DL, Jr, Zhao JL, Coey U, Green JV. Acetylcholine-induced vasodilation is mediated by nitric oxide and prostaglandins in human skin. J Appl Physiol. 2005;98:629-32.

18. Rubanyi GM. Endothelium-derived relaxing and contracting factors. J Cell Biochem. 1991;46:27-36. 